\title{
Nanopartikül kolemanit mineralinin ısıl özellikleri ve uygulamada sağlayacağı kazanımlar
}

\author{
Thermal properties of nanoparticle colemanite mineral and its advantages in application
}

\author{
Sezai KUTUK*1,a , Tuba KUTUK SERT ${ }^{2, b}$ \\ ${ }^{1}$ Recep Tayyip Erdoğan Üniversitesi, Turgut Kıran Denizcilik Fakültesi, Gemi Makineleri İsletme Mühendisliği Bölümü, 53900, Rize \\ ${ }^{2}$ Recep Tayyip Erdoğan Üniversitesi, Mühendislik ve Mimarlık Fakültesi, İnşaat Mühendisliği Bölümü, 53100, Rize
}

• Geliş tarihi / Received: 19.11.2019 • • Düzeltilerek geliş tarihi / Received in revised form: 15.11.2020 • Kabul tarihi / Accepted: 30.12 .2020

\begin{abstract}
$\ddot{O} z$
Kolemanit minerali (C-3 mm) ve ögütülmüş kolemanit mineralleri (C-75 $\mu \mathrm{m}$ ile C-45 $\mu \mathrm{m}$ tozları) Eti Maden Bigadiç Bor İşletme Müdürlüğünden tedarik edildi. C-3 mm başlangıç malzemesi yüksek enerjili bilyalı değirmende öğütme işlemine tabi tutuldu. Akabinde bu malzeme mikronaltı boyutlu/nano boyutlu partiküller üretebilmek amacıyla ASTM standardındaki boyutu $25 \mu \mathrm{m}$ olan bir elekten geçirildi (C-25 $\mu \mathrm{m})$. C-3 mm mineralinin, C-75 $\mu \mathrm{m}$ tozunun, C-45 $\mu \mathrm{m}$ tozunun ve C-25 $\mu \mathrm{m}$ tozunun 1sıl özellikleri TermoGravimetri (TG)/Diferansiyel Termal Analiz (DTA) cihazı ile belirlendi. DTA ölçümünde, ilk ayrışma sıcaklığı C-3 mm minerali için $406^{\circ} \mathrm{C}^{\prime}$ de yüksek şiddete sahip endotermik bir pik ile gözükürken, C-25 $\mu \mathrm{m}$ tozu için $388^{\circ} \mathrm{C}$ 'de endotermik bir pik ile ortaya çıktı. Diferansiyel TG ölçümünde, ilk ayrışma sıcaklığı $\mathrm{C}-3 \mathrm{~mm}$ minerali için $403^{\circ} \mathrm{C}$ 'de yüksek şiddete sahip dar endotermik bir pik ile belirdi ve C-25 $\mu \mathrm{m}$ tozu için de $388^{\circ} \mathrm{C}$ 'de endotermik bir pik ile ortaya çıktı. Önceki bir çalışmada, C-75 $\mu \mathrm{m}, \mathrm{C}-45 \mu \mathrm{m}$ ile C-25 $\mu \mathrm{m}$ tozları Portland çimentolu betona farklı oranlarda ilave edilmiştir. Çalışma sonunda betonun basınç dayanımında belirgin bir artış gözlemlendiği rapor edilmiştir. Bu bulguların nano boyutlu bor mineralleri ile alakalı mühendislik araştırmalarına ışık tutacağı düşünülmektedir.
\end{abstract}

Anahtar kelimeler: Bilyalı öğütme, Bor, Isıl özellik, Kolemanit minerali, Nanopartikül, TG/DTA

\begin{abstract}
Colemanite mineral $(C-3 \mathrm{~mm})$ and milled colemanite minerals (C-75 $\mu \mathrm{m}$ and $C-45 \mu \mathrm{m}$ powders) were obtained from Eti Maden Bigadic Boron Operation Directorate. The C-3 mm initial material was milled in a high-energy ball mill. This material was then sifted using a sieve with a size of $25 \mu \mathrm{m}$ according to the ASTM standard (C-25 $\mu \mathrm{m})$ for the purpose of producing submicron-sized/nano-sized particles. Thermal properties of the C-3 mm mineral, $C$-75 $\mu \mathrm{m}$ powder, $C-45 \mu \mathrm{m}$ powder and C-25 $\mu$ m powder were examined using ThermoGravimetry (TG)/Differential Thermal Analysis (DTA) device. In DTA measurement, first decomposition temperature appeared with a high intensity endothermic peak at $406^{\circ} \mathrm{C}$ for the $C-3 \mathrm{~mm}$ mineral and existed with an endothermic peak at $388^{\circ} \mathrm{C}$ for the $C-25 \mu \mathrm{m}$ powder. In Differential TG measurement, the first decomposition temperature seemed with a high intensity-narrow endothermic peak at $403^{\circ} \mathrm{C}$ for the $\mathrm{C}-3 \mathrm{~mm}$ mineral and occurred with an endothermic peak at $388^{\circ} \mathrm{C}$ for the $C-25 \mu$ m powder. In a previous study, the C-75 $\mu$ m, $C$ $45 \mu \mathrm{m}$ and $\mathrm{C}-25 \mu \mathrm{m}$ powders have been added to Portland cement concrete at varying ratios. Based on the results obtained, it was noted that the compressive strength of concrete increases significantly. Such findings are thought to shed light on engineering research related to nano-sized boron minerals.
\end{abstract}

Keywords: Ball milling, Boron, Thermal property, Colemanite mineral, Nanoparticle, TG/DTA

\footnotetext{
*a Sezai KUTUK; sezai_kutuk@ @otmail.com, sezai.kutuk@erdogan.edu.tr, Tel: (0464) 3111071 (2647), orcid.org/ 0000-0002-0159-5953

${ }^{\mathrm{b}}$ orcid.org/ 0000-0003-1747-9946
} 


\section{Giriş}

Bor elementi periyodik cetvelde IIIA grubunda yer almaktadır. Ancak genelde bir ametal elementi olarak kabul edilmesine rağmen, bazı metal özellikler de sergilemektedir. Bor doğada eser miktarda bulunur, fakat onun büyük bir çoğunluğu bor okso bileşiklerini (B-O bağları) ihtiva eden kolemanit, üleksit, tinkal ve benzeri gibi minerallerden elde edilmektedir. Türkiye rezerv açısından \%73.2'lik bir pay ile dünya çapında zengin bor minerali yataklarına sahiptir (EtiMaden, 2013; Yunlu, 2016). Konuya ilişki olarak yalnızca Türkiye'de değil, dünyada da giderek Ar-Ge çalışmaları artmaktadır. Endüstrinin talep ettiği ürünler bakımından, araştırmacılar doğal boratlardan kolemanit minerali (dikalsiyum hegzaborat pentahidrat, $2 \mathrm{CaO} \cdot 3 \mathrm{~B}_{2} \mathrm{O}_{3} \cdot 5 \mathrm{H}_{2} \mathrm{O}$ ) üzerine yoğunlaşmıştır. Çünkü bu mineral, toz/sıvı deterjanlar, dezenfektan, kozmetik ürünleri, gübre, tarım ilacı, fotoğrafçılık kimyasalları, cam, tekstil tipi cam elyafı, sir ve emaye kaplamaları, naylon, metalürjik cüruflar, yağlayıcılar, nükleer santraller, mıknatıs, süperiletken malzeme, aşırı yüksek sicaklık seramiği, radyasyondan koruyucu malzeme, alev geciktirici malzeme, cam elyaf bazlı yalıtım malzemesi, ahşap koruma malzemesi, asfalt beton, borlu çimento, çimento betonu vb. gibi pek çok endüstriyel kullanım alanlarına sahiptir ve sahip olacaktır (Kutuk, 2017).

Son zamanlarda farklı ülkelerden bilim adamları, nano boyutlu malzemelerin mekanik, 1s1, elektriksel ve manyetik özelliklerinin daha iyi sonuçlar sergilediğini ifade etmektedir (Han vd., 2017; Shariatmadar ve Pakdehi, 2017). Bir malzemeyi iri taneli boyuttan küçük taneli boyuta indirgemek için pek çok yöntem vardır. Elbette maliyet hesabı dikkate alındığında, en cazip yöntemlerden birisi de yüksek enerjili bilyalı değirmende ögütme işlemidir (Alizadeh vd., 2015). $\mathrm{Bu}$ tip değirmende malzeme tekrar eden deformasyon-kırılma-soğuk kaynak mekanizması olan katıhal tepkime sürecine maruz bırakılmaktadır (Canakci vd., 2014).

Hem ögütülmüş hem de elenmiş kolemanit minerallerinin $(\mathrm{C}-75 \mu \mathrm{m}, \mathrm{C}-45 \mu \mathrm{m}$ ve C-25 $\mu \mathrm{m}$ tozlar1) katk1 malzemesi olarak beton yollara ilave edildiği bir çalışma (Kutuk-Sert, 2016) rapor edildi. Multidisipliner çalışmanın ilk aşamasında bu minerallerin partikül boyut dağılım (PSD) ölçümleri, optik mikroskop ve taramalı elektron mikroskop (SEM) görüntüleri alındı. Sonuçta, en iyi ortalama partikül boyutuna sahip olan tozun C$25 \mu \mathrm{m}$ olduğu ve onun değerinin $\left(d_{50}\right)$ ise $8.111 \mu \mathrm{m}$ olduğu belirlendi. Ayrıca, en küçük partikül boyutuna sahip tozun C-25 $\mu \mathrm{m}$ olduğu ve onun değerinin $\left(d_{\min }\right)$ ise $316 \mathrm{~nm}$ (mikronaltı) olduğu tespit edildi. Çalışanın son aşamasında, bu mineraller ağıl11kça $\% 0$ ila 5 oranlarda yol betonuna ilave edildi. Neticesinde, betonun basinç dayanımının \%11 oranı ile önemli bir artış gösterdiği tespit edilmiştir. Bu artışın nedeni, C-25 $\mu \mathrm{m}$ tozunun mikronaltı partiküllere sahip olduğu için agrega-çimento hamuru ara yüzeyi arasındaki boşlukları daha iyi doldurarak daha kuvvetli bir aderans sağlandığı düşüncesine dayandırıldı.

C-75 $\mu \mathrm{m}, \mathrm{C}-45 \mu \mathrm{m}, \mathrm{C}-25 \mu \mathrm{m}$ tozlarının elementel ve kristal yapı özellikleri ile alakalı bir araştırma (Kutuk, 2017) yayımlandı. Araştırmada, Eti Maden Bigadiç Bor İşletme Müdürlüğünden temin edilen iri taneli kolemanit minerali $(\mathrm{C}-3 \mathrm{~mm})$, önce yüksek enerjili bilyalı bir değirmende öğütme işlemine tabi tutuldu ve daha sonra titreşimli elek sarma cihazında elendi (C-25 $\mu \mathrm{m}$ tozu). Tozda herhangi bir kirlenmenin olmadığ oksitli bileşen miktarının hemen hemen değişmediği saptandı. Ek olarak, C-25 $\mu$ m tozunun ortalama kristalit boyutu $63.6 \mathrm{~nm}$ değeri ile nano boyuta (nanokristal) başarılı bir biçimde indirgendi.

Kolemanit mineralinin 1sıl özelliklerini bilmek, endüstri açısından önem arz eder. Çünkü malzemelere kolemanit katkısı yapılması ile onların ergime noktas1, viskozitesi ve 1s1l genleşmesi azalır. Dolayısıyla onların 1sıl direnci, mekanik dayanımı ve kimyasal stabilitesi artar (Akpinar vd., 2017). Malzemelerin 1s1l direncinin yüksek olması, 1sıl şoklara karş1 malzemeyi kullanabilir hale getirmektedir. İște bu yüzden, birçok endüstride özellikle $\% 52$ 'lik bir dilime sahip olan cam endüstrisinde bu tür malzemeler hummalı bir şekilde çalışılmaktadır (Yunlu, 2016).

Karayolu iklimsel değişikliklerden en çok etkilenen yapılardandır. Beton yollar açısından bakıldığında sıcak iklimlerde hidratasyon problemleri; ılıman ve yağmurlu iklimlerde 1slanma-kuruma döngüsüne bağlı olarak ortaya çıkan su hassasiyeti; soğuk iklimlerde ise donmaçözülme döngüsünün beraberinde getirdiği çatlama oluşumları en sik karşılaşılan problemlerdir. Bu bağlamda, farklı 1sıl şartlara maruz bırakılmış betonların 1sıl ve mekanik özeliklerinin araştırıldığ bir çalışmada (Rios vd., 2018) yüksek sıcaklığın betonlar üzerinde önemli etkileri olduğu ortaya konulmuştur. Yine başka bir çalışmada (Barluenga vd., 2018) kendinden yerleşen betonlarda (SCC) sıcak-kuru iklim şartlarının ilk evre çimento hidratasyonunu hızlandırdığı ve poroziteyi artırdığı rapor edilmektedir. 
Betonun sıcaklık etkisinin en fazla gözlendiği alan karayolu beton kaplama uygulamalarıdır. Diğer mühendislik yapılarında beton yüzeyi dış cephe kaplaması, sıva ve boya gibi uygulamalarla dış ortam etkenlerinden izole edilmektedir. Ancak yol yapısında durum tamamen farklıdır. Beton yüzeyi dış ortam etkilerine (sıcaklık değişimleri, yağış ve suya temas, don ve buzlanma etkileri ile tekerleğin yüzeye uyguladığı mekanik etkiler ve basınç değişimleri gibi) açıktır ve bu tür etkilerle doğrudan temas halindedir. Bundan dolayı beton yol uygulamaları önem teşkil eder. Beton yol plakları bunlar içerisinde en çok sicaklık değişimlerinden etkilenmektedir. Beton yol gündüz ve gece sicaklık değişimlerinde farklı davranışlar göstermektedir. Gündüz saatlerinde plağın üst yüzey sıcaklığı alt sicaklığından daha yüksektir ve konkav davranış gösterir. Yani üst kısım genleşirken alt kısım büzülmektedir. Gece saatlerinde ise plağın üst yüzey sıcaklığının alt yüzeyden daha düşük olması tam aksi bir durum ortaya çıkmasına sebep olmaktadır. Başka bir ifadeyle, üst kısmın büzülmesine karşılık alt kısım genleşecek yani konveks şekil alacaktır. Bu durumun gündüz-gece döngüsü boyunca sürekli oluşması gerilmelerin artmasına ve dolayısıyla betonun deformasyonuna sebep olacaktır. Beton plağı köşelerinin de orta kısımla aynı zamanda ağır trafik yüklerine maruz kalması, beton plağın tamamını etkileyen yanal çatlaklar meydana gelmesine sebebiyet verecektir (Pancar ve Akpinar, 2016). Yapılmış olan bir araştırmada (Pancar, 2016) zeolit minerali değişik oranlarda beton yol numunelerine ikame edilerek plaka yüzey sıcaklığı belirlenmiştir. Zeolit ikamesiyle hem betonun basınç dayanımının $\% 8$ arttığı hem de yüzey sıcaklığının $50^{\circ} \mathrm{C}^{\prime}$ den $38^{\circ} \mathrm{C}^{\prime}$ ye düştüğü tespit edilmiştir.

Kolemanit minerali, nötron radyasyonundan koruyucu malzeme olması için betonda agrega olarak kullanımı ile ilgili bir makale yayımland 1 (Lotti vd., 2019). Doğal borat halde ve $\mathrm{B}_{2} \mathrm{O}_{3}$ miktarı ağırlıkça \%50.8 değerinde olan kolemanit minerali havanda öğütülerek homojen toz haline getirilmiştir. Agrega olarak kullanılan bileşiklerin içsel anizotropisinin ve hacimsel isısal genleşmesinin, betonun yüksek sıcaklık davranışını kontrol etmede uygun olduğu ifade edilmiştir. $\mathrm{Bu}$ sebep ile kolemanit mineralinin 1sısal elastik davranışı araştırılmış ve $25-325^{\circ} \mathrm{C}$ aralığındaki sicaklığın fonksiyonu olarak çevre koşullarında hacimsel ısıl genleşme katsayısı $(\alpha)$ 4.5.10 $\mathrm{K}^{-1}$ olarak hesaplanmıştır. Sicaklık kaynaklı yapısal dönüşümler en az $250^{\circ} \mathrm{C}$ ve üzerinde imalat endüstrisinde ekonomik istikrarını etkileyebileceği için, kolemanit mineralinin (kristal yapıda) kullanımda 1sı özelliğinin dikkate alınması tavsiye edilmiştir.

Beton yüksek sıcaklığı maruz kaldığı zaman, kimyasal kompozisyonu ve fiziksel yapısı oldukça değişmektedir. Mikroyapısal değişikliklere sebep olan yüksek sicaklık etkisinin sonucu olarak, beton dayanımını ve durabilitesini kaybeder. Beton dayanımındaki bozulma $200^{\circ} \mathrm{C}$ 'nin altında oluşur, ancak $400^{\circ} \mathrm{C}^{\prime}$ nin üzerinde çok daha önemlidir. $\mathrm{Bu}$ yüzden, yangına dayanıklı malzemeleri üretebilmek için yüksek sıcaklıklarda yüksek performans gösteren betona uygun agrega seçimine dikkat edilmelidir. Pomza agrega kaplanmış kolemanit minerali ile hazırlanan hafif betonlar üzerindeki yüksek sıcaklık $\left(20-1000^{\circ} \mathrm{C}\right)$ etkisiyle alakalı bir araştırma rapor edildi (Sallı Bideci, 2016). Kolemanit minerali katk1lı numunelerin basınç dayanımda pozitif sonuçlar bulunmuş ve ayrıca maksimum basınç dayanımı $31.4 \mathrm{MPa}$ değeri ile $200^{\circ} \mathrm{C}$ 'deki $\% 12.5$ katkılı numunede gözlenmesine karşın, en düşük basınç dayanımı ise 11.2 $\mathrm{MPa}$ değeri ile $600^{\circ} \mathrm{C}$ 'deki kontrol numunesinde elde edilmiştir.

Oranlar1 $\% 5$ ve $\% 10$ olan mikron partikül boyutlu $(\mathrm{C}+53 \mu \mathrm{m})$ ve nanopartikül boyutlu kolemanit mineralleri $(\mathrm{C}-25 \mu \mathrm{m})$ katkısı yapılmış 1lık karışım asfalt (WMA) kaplamaların düşük sıcaklık performans1, sünme rijitliği ölçümden değerlendirilmiştir (Kutuk ve Kutuk-Sert, 2020). $\% 5 \mathrm{C}+53 \mu \mathrm{m}, \% 10 \mathrm{C}+53 \mu \mathrm{m}, \% 5 \mathrm{C}-25 \mu \mathrm{m}$ ve $\% 10 \mathrm{C}-25 \mu \mathrm{m}$ katkılı karışımların sünme rijitlik değerleri $108 \mathrm{MPa}, 106 \mathrm{MPa}, 239 \mathrm{MPa}$ ve 225 MPa'dır ve tüm değerler $300 \mathrm{MPa}$ sınırının altında kaldığı için uygulama koşulunu sağlamaktadır. Bununla birlikte $113 \mathrm{MPa}$ (Ref_adv) ve $150 \mathrm{MPa}$ (Ref_b) değerlerine sahip kontrol karışımlarına göre mikron partikül boyutlu karışımların rijitlik değerleri daha azdır. Yani, 1sıl çatlaklara karşı asfalt direncinin mikron boyutlu partikül ilavesi ile arttı̆g 1 ve dolayısıyla uygulamada mikron partikül boyutlu kolemanit mineralinin kullanımın daha uygun olacağı belirtilmiştir.

Literatürde 1 sıl özellik açısından kolemanit minerali hakkında yeteri kadar bilgi olmasına rağmen, nanopartikül boyutlu ve nanokristal boyutlu kolemanit minerali hakkında benzeri sonuçlara rastlanmadı. Bu çalışmanın amacı, nano boyuta ögütülen kolemanit mineralinin 1sıl özellikler üzerindeki etkisini araştırmaktır. Dahası ve önemlisi, elde edilen ölçümlerin mühendislik açısından bir değerlendirmesini yapmak ve irdelemektir. 


\section{Materyal ve metot}

\subsection{Materyal}

$\mathrm{Bu}$ çalışmada kullanılan doğal/ham kolemanit mineralleri, Eti Maden İşletmeleri Genel Müdürlüğü Bigadiç Bor İşletme Müdürlüğünden tedarik edilmiştir. $\mathrm{Bu}$ mineraller, detayı daha önceki bir çalışmada (Kutuk, 2017) verilen C-3 $\mathrm{mm}, \mathrm{C}-75 \mu \mathrm{m}, \mathrm{C}-45 \mu \mathrm{m}$ boyutunda minerallerdir.

\subsection{Metot}

Toz teknolojisi açısından yapılan öğütme ile eleme işlemleri, Recep Tayyip Erdoğan Üniversitesi Mühendislik Fakültesi İnşaat Mühendisliği Ulaştırma Anabilim Dalı NanoBor ve Yol Üstyapı Araştırma Laboratuvarı'nda gerçekleştirildi.

Nano boyutlu kolemanit üretebilmek amaciyla, iri taneli halde olan C-3 mm malzemesi düzlemsel yüksek enerjili bilyalı bir değirmende öğütme işlemine tabi tutuldu. Öğütme yöntemi ile ilgili ayrıntılı bilgi başka çalışmalarda (Kutuk, 2016; Kutuk ve Kutuk-Sert, 2017) mevcuttur.

Ultra ince taneli yani toz halde olan ögütülmüş malzeme, titreşimli sarsma cihazı kullanılarak 25 $\mu \mathrm{m}$ göz açıklıklı elekten elendi ve kolaylık açısından C-25 $\mu \mathrm{m}$ olarak etiketlendi. Eleme yöntemi ile alakalı detaylı bilgi başka bir araştırmada (Kutuk, 2017) mevcuttur.
Başlangıç malzemeleri ile öğütülmüş toza ait TermoGravimetri (TG) ve Diferansiyel Termal Analiz (DTA) ölçümleri, simültane 1s1l analiz cihazı (Netszch, model 'STA 449 F3 jüpiter') ile Eti Maden İşletmeleri Genel Müdürlügü Teknoloji Geliştirme Dairesi Başkanlığı Laboratuvarından sağlanmıştır. Bu laboratuvar TS EN ISO/IEC 17025 standardına ve AB 0403-T akreditasyon sertifikasına sahiptir. TG/DTA ölçümleri 25$1000^{\circ} \mathrm{C}$ sicaklığında, $10^{\circ} \mathrm{C} / \mathrm{dk}$ ssıtma hizı ve azot atmosferi şartlarında gerçekleştirilmiştir.

\section{Bulgular ve tartışma}

Başlangıç C-3 mm malzemesine ait TG/DTA eğrileri Şekil 1'de verilmektedir. C-3 mm malzemesinin TG (kütle değişimi) değeri 25$400^{\circ} \mathrm{C}^{\prime} \mathrm{de} \% 99$ 'a, $400-500^{\circ} \mathrm{C}$ 'de \%89'a, 500$700^{\circ} \mathrm{C}$ 'de $\% 86$ 'ya ve $700-900^{\circ} \mathrm{C}$ 'de $\% 75$ 'e düsstüğü görülmektedir. C-3 mm malzemesinin DTG (kütle değişimindeki fark) eğrisinde $403^{\circ} \mathrm{C}$ 'de yüksek şiddete sahip dar bir pike rastlanmıştır. C-3 mm malzemesinin DTA eğrisinde $406^{\circ} \mathrm{C}$ 'de yüksek bir tane endotermik pik ve $843^{\circ} \mathrm{C}$ küçük bir tane endotermik pik tespit edilmiştir. Burada $406^{\circ} \mathrm{C}$ 'deki pik, kolemanitin karakteristik pik değeridir (Waclawska, 1997a). Bu verilere göre, $400^{\circ} \mathrm{C}$ civarında büyük bir ayrışmanın meydana geldiği anlaşılmıştır. Bunun nedeni, kristal yapıdan (saf kolemanit: $2 \mathrm{CaO} \cdot 3 \mathrm{~B}_{2} \mathrm{O}_{3} \cdot 5 \mathrm{H}_{2} \mathrm{O}$ ) $\mathrm{OH}$ bağlarının kopmasıdır, yani $\mathrm{H}_{2} \mathrm{O}$ kristalize suyun belli bir mol değerinin yapıdan uzaklaşmasıdır (Waclawska, 1997a, b).

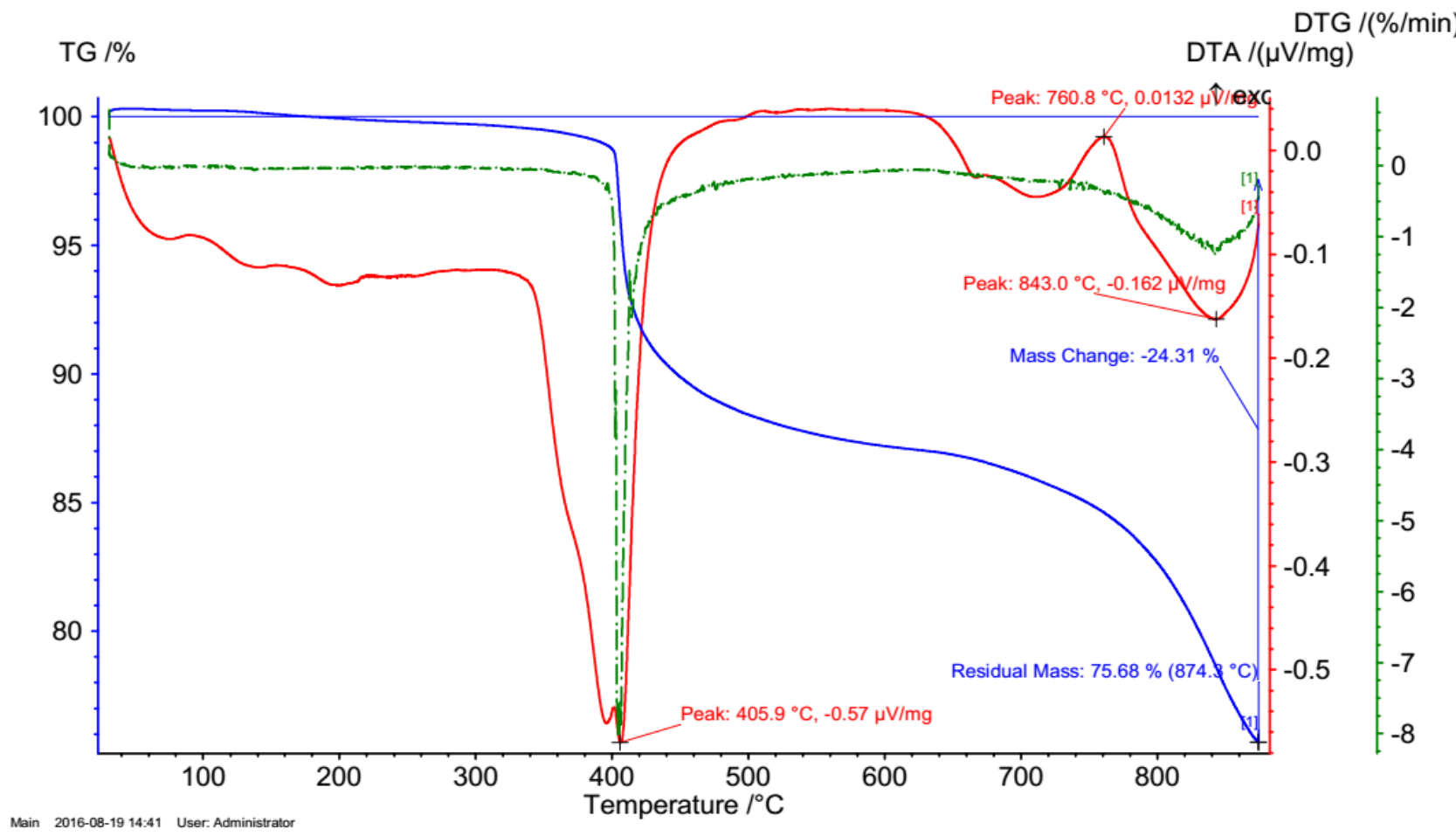

Şekil 1. Başlangıç C-3 mm malzemeye ait TG/DTA eğrileri 
Şekil 2, başlangıç C-75 $\mu \mathrm{m}$ tozun TG/DTA eğrilerini göstermektedir. TG, DTG ve DTA eğrileri analiz edildiğinde, C-75 $\mu \mathrm{m}$ tozun küçük bir farkla C-3 mm malzemesine ait eğriler ile aynı olduğu görülmektedir. Lotti vd. (2019) yapmış olduğu havanda ögütülmüș kolemanit mineralinin $25-500^{\circ} \mathrm{C}$ aralığındaki TG eğrileri, C-75 $\mu \mathrm{m}$ tozun TG eğrileri ile benzer davranış sergilemektedir. Birincisi, $50^{\circ} \mathrm{C}^{\prime}$ nin üzerinde dehidrasyon sürecinin başlamasıdır. İkincisi, $275^{\circ} \mathrm{C}$ de ağırlıkça yaklaşık $\% 1$ kaybın olmasıdır ve bunun nedeni $\mathrm{x}$-1şını difraktometresi (XRD) ölçüm sonucuna göre $\mathrm{H}_{2} \mathrm{O}$ oksijen $\mathrm{O} w$ yerinin arıtılmış doluluğunun 1.0'den az olmasıdır, yani nem veya yüzeysel suya atfedilmektedir. Üçüncüsü, $325^{\circ} \mathrm{C}$ 'de ağırlıkça yaklaşık $\% 2$ kaybın olmasıdır ve dehidrasyon olayı kolemanit mineralinin kristal örgü parametrelerini ( $a$ ve $c$ azalırken, $b$ artt1) ciddi derecede etkilemiştir. $\mathrm{Bu}$ durum oksitli bileşen analizinde verilen ağırlıkça \%21.8 (5 mol) olan kristalize suyun (bu değerin içeriği büyük olasılıkla 16.0 hidroksil gruplarından ve $5.8 \mathrm{H}_{2} \mathrm{O}$ moleküllerinden ibarettir) \%2'lik miktarının kristal yapıdan ayrıştığı anlamina gelmektedir. Son olarak, $500^{\circ} \mathrm{C}^{\prime} \mathrm{de}$ ağırlıkça yaklaşık \%23 kaybın olmasıdır ve bu durum kristalize suyun tamaminin yapidan ayrıştığını (anhidrit kolemanit) belirtmektedir.

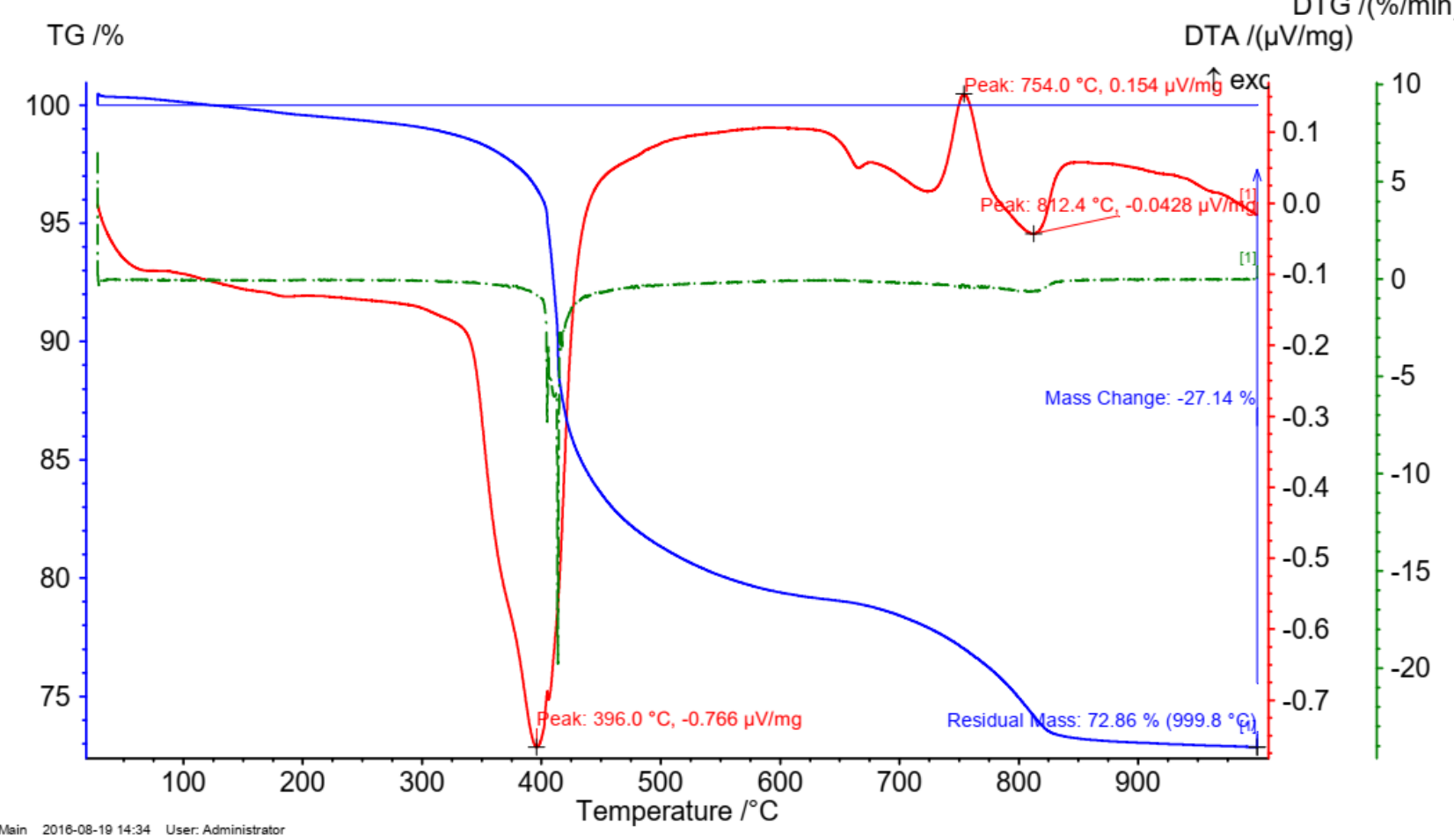

Şekil 2. Başlangıç C-75 $\mu \mathrm{m}$ tozuna ait TG/DTA eğrileri

Başlangıç C-45 $\mu \mathrm{m}$ tozun TG/DTA eğrileri Şekil 3 'de verilmektedir. TG, DTG ve DTA eğrileri incelendiğinde, $\mathrm{C}-45 \mu \mathrm{m}$ tozun büyük bir farkla C$3 \mathrm{~mm}$ malzemeye ait eğrilerinden oldukça farklı olduğu saptand1. $\mathrm{Bu}$ durumun tozun üretim yöntemi ile alakalı olduğu ve ayrıca aşağıda açıklandığ1 gibi öğütülmüş $\mathrm{C}-25 \mu \mathrm{m}$ tozunun durumu ile aynı olduğu düşünülmektedir. 
TG $/ \%$ DTA $/(\mu \mathrm{V} / \mathrm{mg})$

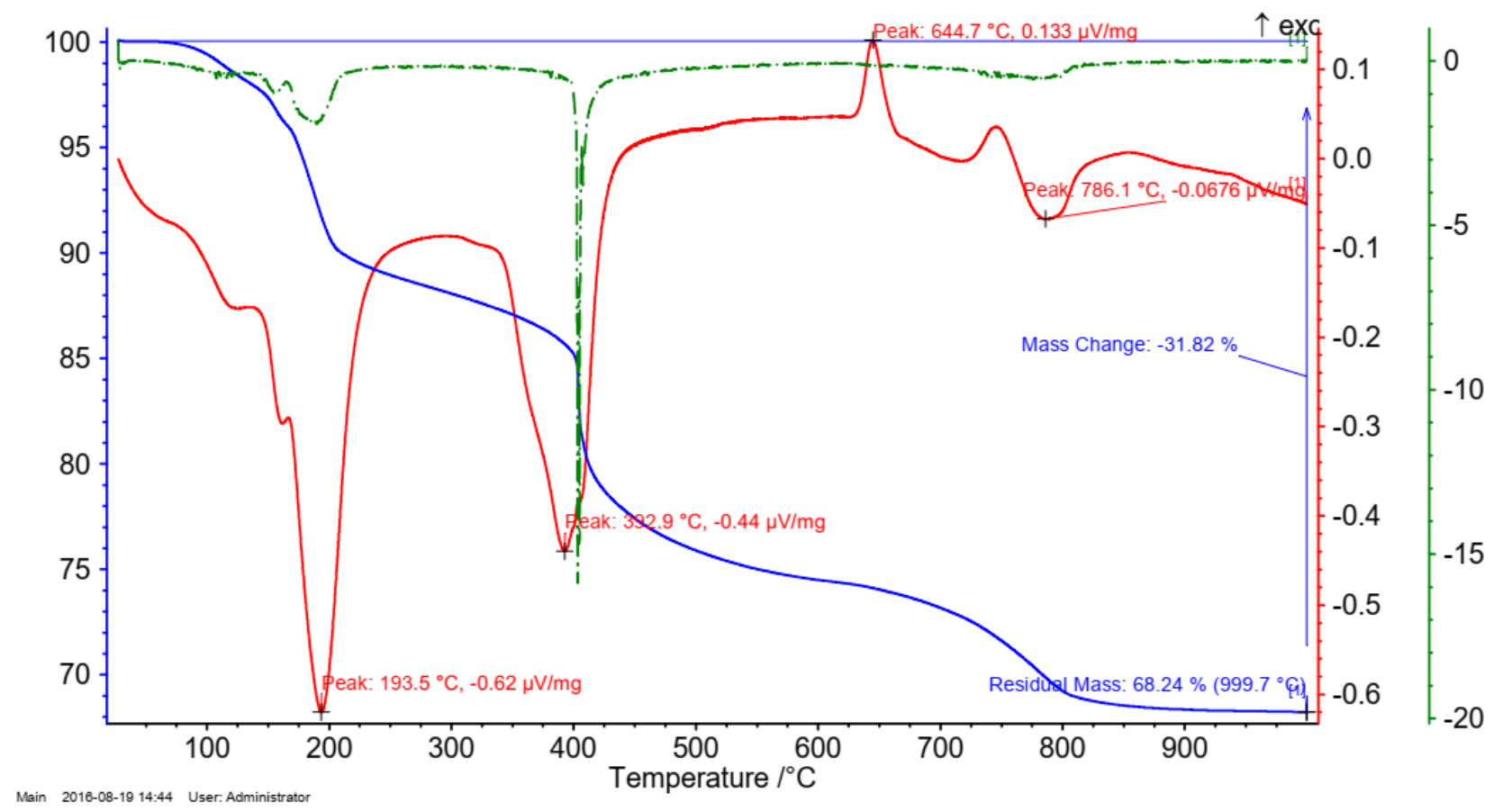

Şekil 3. Başlangıç C-45 $\mu \mathrm{m}$ tozuna ait TG/DTA eğrileri

Şekil 4, öğütülmüş C-25 $\mu \mathrm{m}$ tozuna ait TG/DTA eğrilerini göstermektedir. Ögütülmüş C-25 $\mu \mathrm{m}$ tozuna ait TG değeri, $25-400^{\circ} \mathrm{C}^{\prime} \mathrm{de} \% 92$ 'ye, 400 $500^{\circ} \mathrm{C}$ 'de $\% 88$ 'e, $500-700^{\circ} \mathrm{C}$ 'de $\% 82$ 'ye ve 700 $900^{\circ} \mathrm{C}$ 'de $\% 73$ 'e düştüğü görülmektedir. C-3 mm malzemesi ile karşılaştırıldığı zaman, C-25 $\mu \mathrm{m}$ tozuna ait TG değerleri daha küçüktür. Bu durum ilk başlarda daha etkindir. Başka bir deyişle, C-25 $\mu \mathrm{m}$ tozuna ilişkin kütle kaybı orta sıcaklıklarda daha fazla iken yüksek sıcaklıklarda azalış sergilemektedir.

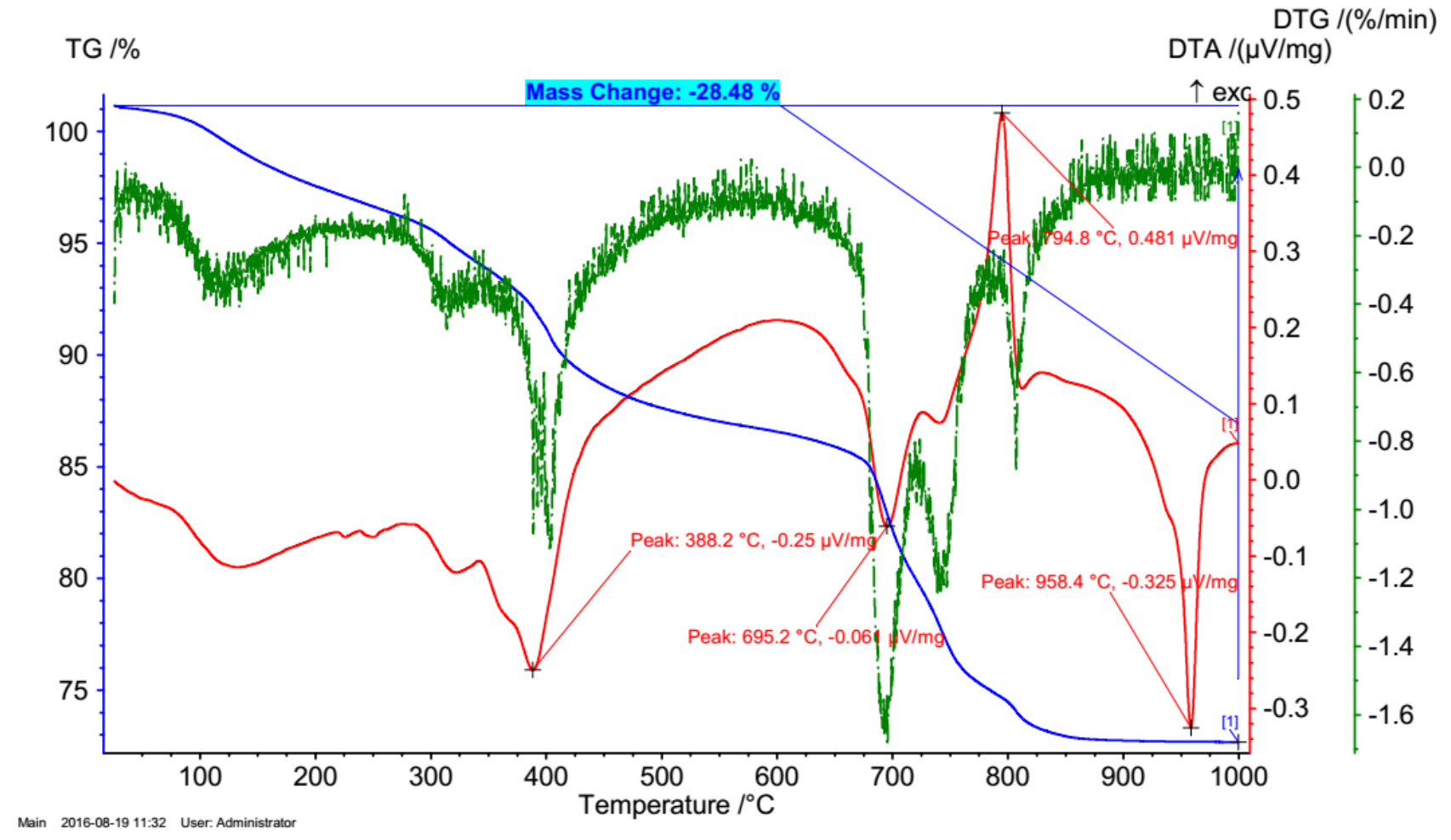

Şekil 4. Öğütülmüş C-25 $\mu \mathrm{m}$ tozuna ait TG/DTA eğrileri 
$\mathrm{C}-25 \mu \mathrm{m}$ tozuna ait DTG eğrisinde $388^{\circ} \mathrm{C}$ 'de, $690^{\circ} \mathrm{C}^{\prime} \mathrm{de}, 740^{\circ} \mathrm{C}$ 'de ve $810^{\circ} \mathrm{C}$ 'de dört tane pik vardır. C-3 mm malzeme ile mukayese edildiğinde, $\mathrm{C}-25 \mu \mathrm{m}$ tozuna ait DTG eğrisindeki pik sayısının artmış olduğu görülmektedir. Ayrıca, C-3 mm malzemeye ait $403^{\circ} \mathrm{C}^{\prime}$ deki pik ögütme işlemi neticesinde $15^{\circ} \mathrm{C}$ azalarak $388^{\circ} \mathrm{C}$ ye düşmüştür. Böyle bir düşüş, başka bir çalışmanın (Uysal vd., 2016) neticesi ile uyumludur.

$\mathrm{C}-25 \mu \mathrm{m}$ tozuna ait DTA eğrisinde $388^{\circ} \mathrm{C}^{\prime}$ de ve $695^{\circ} \mathrm{C}$ 'de endotermik pikler ve ayrıca $795^{\circ} \mathrm{C}$ 'de ekzotermik bir pik gözlemlenmiştir. C-3 mm malzemesi ile kıyaslandığında, $\mathrm{C}-25 \mu \mathrm{m}$ tozuna ait DTA eğrisinde pik sayısının artmış olduğu saptandi. Ek olarak, C-3 mm malzemeye ait $406^{\circ} \mathrm{C}$ 'deki pikin öğütme işlemi neticesinde $18^{\circ} \mathrm{C}$ azalarak $388^{\circ} \mathrm{C}$ ye düștüğü belirlendi. Bu bulgu literatürdeki (Ma vd., 2013) mevcut bulgu ile örtüşmektedir. Borlu bir bileşik $\left(\mathrm{MgB}_{2}\right)$ yüksek enerjili bilyalı bir değirmende sentezlendiğinde öğütme zamanının artışına bağlı olarak DTA eğrisindeki ana pikin hem sicaklık değerinin azaldığı hem de pik şiddetinin düştüğü tespit edilmiştir.

PSD ve SEM analizlerine göre kolemanit mineralinin partikül boyutunda mikronaltı ölçeğe indirgendiği (Kutuk-Sert, 2016) ve üstelik XRD analizine göre onun kristalit boyutunda nano ölçeğe indirgendiği (Kutuk, 2017) daha önce yayınlanmıştır. Sunumu yapılan bir çalışmada (Kutuk ve Kutuk-Sert, 2019) ise, yüksek çözünürlüklü geçirimli elektron mikroskop (HRTEM) görüntüsüne göre kolemanit mineralinin partikül boyutunda nano ölçek Şekil 5'te gösterildiği gibi gözlemlenebilmiştir. Böylece C$25 \mu \mathrm{m}$ tozu ile $36 \mathrm{~nm}, 30 \mathrm{~nm}, 28 \mathrm{~nm}, 19 \mathrm{~nm}$ gibi $100 \mathrm{~nm}$ 'nin altındaki partiküller (nanopartikül) elde edilmiş oldu. Son olarak bu çalışmada, TG/DTA verilerine göre kolemanit mineraline ait kristalize suyun sadece ayrışma sıcaklığının düştüğü değil, aynı zamanda miktarının da azaldığı belirlenmiştir. Kolemanit mineralinin sicaklık parametresiyle alakalı mühendislik uygulamalarında bu durumun dikkate değer olduğu düşünülmektedir.

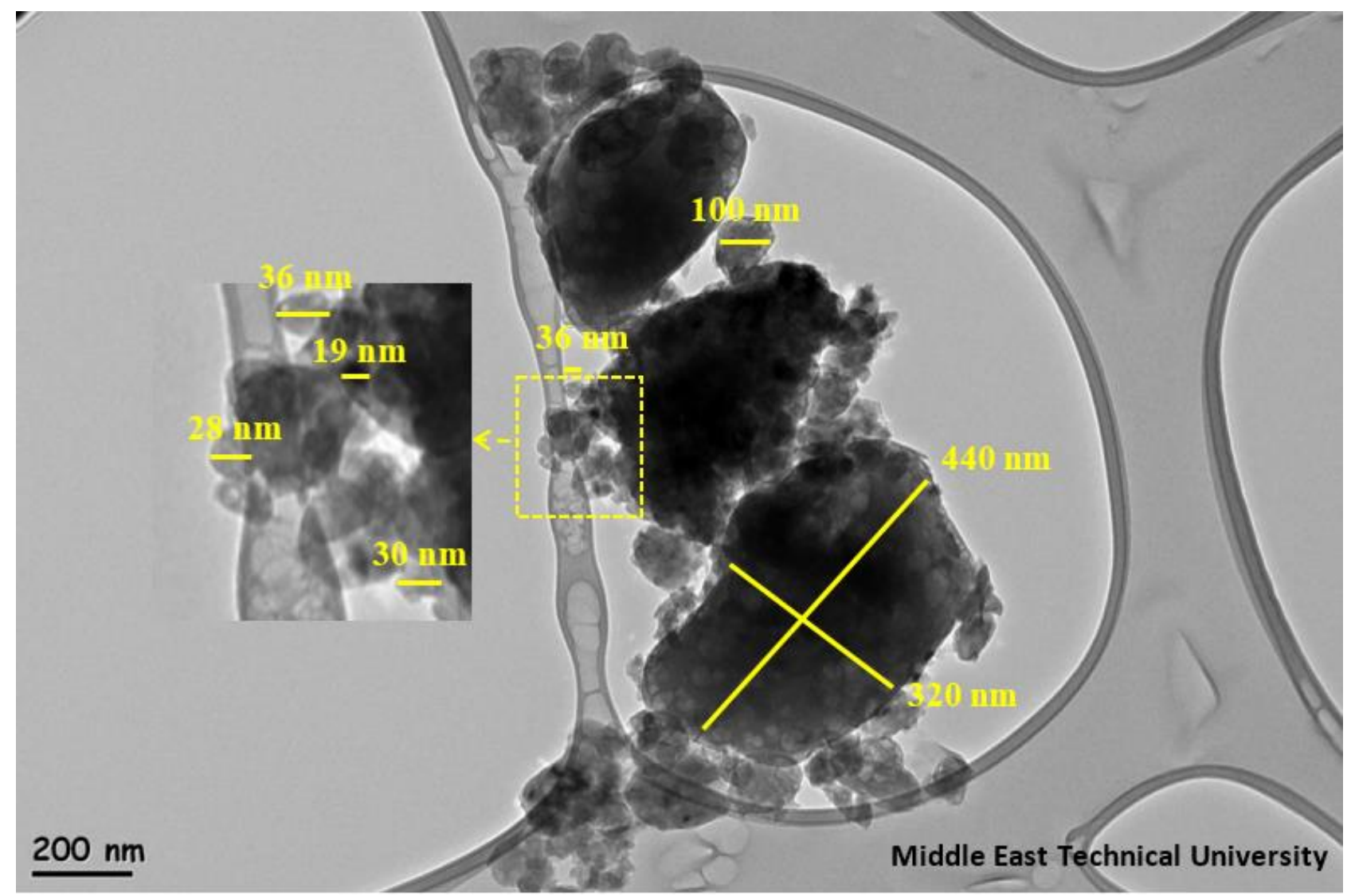

Şekil 5. Ögütülmüş C-25 $\mu \mathrm{m}$ tozuna ait HR-TEM görüntüsü

C-75 $\mu \mathrm{m}, \mathrm{C}-45 \mu \mathrm{m}$ ve C-25 $\mu \mathrm{m}$ tozları mineral katk1 malzemesi olarak beton yol numunelerine ilave edilmiş ve böylece numuneler üretilerek basınç dayanımları değerlendirilmiştir. Detaylı bilgi başka bir çalışmada (Kutuk-Sert, 2016) rapor edilmektedir. Şekil 6'da görüldüğü üzere, 28 günlük basınç dayanımları tüm kolemanit ilaveli numunelerde referans numuneye göre yüksektir. $\mathrm{Bu}$ sonuç uygulama açısından oldukça değerlidir. C-25 $\mu \mathrm{m}$ tozu ilaveli numunelerin basınç dayanımı 
düşük yüzde oranları için daha büyük iken, yüksek yüzde oranları için ise daha küçüktür. Bunun sebebi önceki çalışmalarda C-25 $\mu \mathrm{m}$ tozunun mikronaltı partikül boyutuna (Kutuk-Sert, 2016), nanokristal yapısına (Kutuk, 2017) ve nanopartikül boyutuna (Kutuk ve Kutuk-Sert, 2019) atfedilmektedir. $\mathrm{Bu}$ çalı̧smada ise, TG/DTA eğrileri sonucunda tespit edilen C-25 $\mu$ m tozunun bünyesindeki kristalize su miktarının daha az olmasına ve ayrıca onun ayrışma sıcaklığının daha düşük olmasına yorumlanabilir. Başka bir ifadeyle, öğütme işlemi neticesinde farklı 1sıl özelliklere sahip olabileceğinden dolayı beton numunelere ilave veya ikame edilmeden önce, mineral katk1 malzemesinin 1 s1l özelliklerinin incelenmesi faydalı olacaktır.

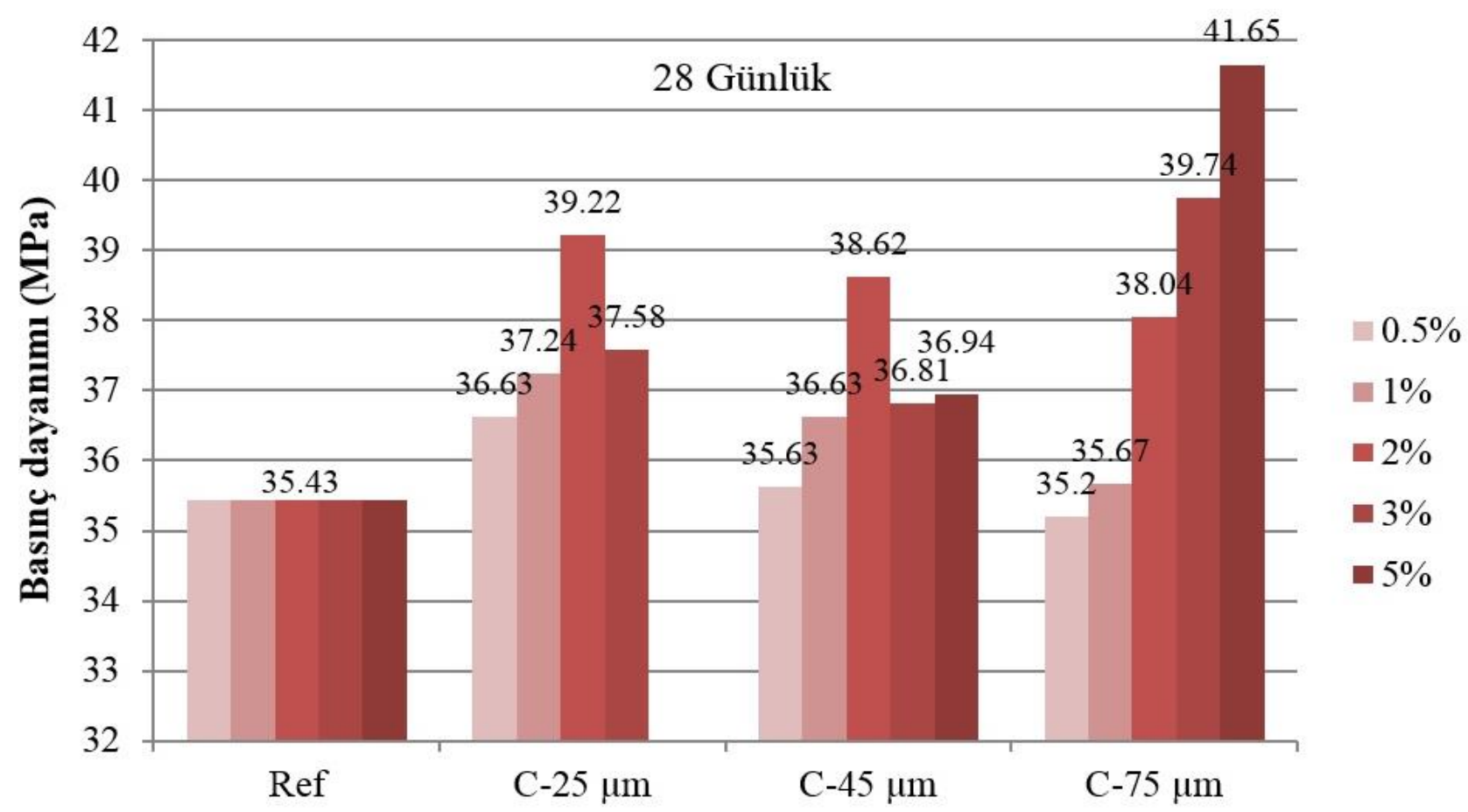

Kolemanit ilaveli beton türü

Şekil 6. Kolemanit ilaveli yol betonu numunelerinin 28 günlük basınç dayanımları (Kutuk-Sert, 2016).

$\mathrm{Bu}$ çalışmadan elde edilen bulgular 1şı̆̆ında, kolemanit minerali ilaveli beton yollarda soğuk ve sıcak iklim şartları hesaba katıldığı zaman, uzun periyotta sıcaklık değişiminden kaynaklı çatlak, su kaybı ve basınç, eğilme, yarmada çekme dayanım kayıları gibi sorunların azalacağı düşünülmektedir. Kolemanit mineralinin $\alpha$ değerinin betonunun $\alpha$ değerinden daha küçük olmasindan dolayı, bu fikre varıldı. Beton yollarda nanofiber mineral katkıların isıl özellikleri $10^{\circ} \mathrm{C}$, $20^{\circ} \mathrm{C}, 30^{\circ} \mathrm{C}, 40^{\circ} \mathrm{C}, 50^{\circ} \mathrm{C}$ ve $60^{\circ} \mathrm{C}$ sicakliklarinda doğrusal $\alpha$ ile ilişkisi bir araştırmada değerlendirilmiştir (Liu vd., 2018). Nanofiber mineral katk1lı beton için $\alpha$ değeri regresyon analizinden $8.7 .10^{-6} \quad{ }^{\circ} \mathrm{C}^{-1} \quad\left(R^{2}=0.97\right) \quad$ olarak hesaplanmıştır. $\mathrm{Bu}$ değerin yaklaşık \%13.9 normal fiber katk1lı betondan ve $\% 28.7$ donatisız betondan daha küçük olduğu tespit edilmiştir. Başka bir deyişle, nanofiber mineral katkılı beton 1s1 deformasyonuna karşı direnmek için daha güçlü kapasiteye sahiptir. Ek olarak 50 donma-çözülme çevriminden sonra, nanofiber minerali katkılı beton numunelerin basınç ve eğilme dayanımlarındaki kayıplar sirasiyla \%3.2 ve \%1.9 normal fiber katk1lı betondan daha az olduğu belirlenmiştir. $\mathrm{Bu}$ sonuç, nano katkılı minerallerin betonda donmaçözülme direncinin daha iyi olduğunu ortaya koymuş ve ayrıca bu çalışmadaki nanopartikülere sahip C-25 $\mu \mathrm{m}$ tozunun benzer etki göstereceğini işaret etmektedir.

Zeolit minerali çeşitli oranlarda beton yol numunelerine ikame edilmiş ve numunelerin plaka yüzey sicaklığı ölçülerek bir çalışmada tartışılmışıır (Pancar, 2016). Zeolit minerali ikamesiyle sadece betonun basınç dayanımının $\% 8$ arttığı değil aynı zamanda yüzey sıcaklığının $12^{\circ} \mathrm{C}$ düştügü tespit edilmiştir. Mineral katk1 kullanılmasının betonun 1s1 iletkenlik katsayısını düşürdügü ve bu yüzden de beton yüzeyinde 1s1 çatlakların azaldığı anlaşılmıştır. Pancar (2016)'ın basınç dayanımında bulmuş olduğu olumlu sonuç, bu çalışmanın basınç dayanımındaki olumlu sonuç ile örtüşmektedir. Buradan yola çıkarak kolemanit minerali katkısının beton yol numunelerindeki yüzey sıcaklığını düşüreceği ve dolayısıyla Şekil 
6'da verilen C-25 $\mu \mathrm{m}$ ilaveli beton numunedeki $\% 11$ 'lik artışın ve C-75 $\mu \mathrm{m}$ ilaveli beton numunedeki \%18'lik artışın 1sıl problemleri daha da azaltacağı beklenmektedir. Üstelik daha sıcak bölgelerde daha yüksek beton yüzey sıcaklığının olacağından dolayı, kolemanit minerali katkısı kullanımının daha da önem arz edeceği tahmin edilmektedir.

Öğütülmüş kolemanit minerali farklı oranlarda hafif beton numunelerine ikame edilmiş ve numunelerin $20^{\circ} \mathrm{C}, 200^{\circ} \mathrm{C}, 400^{\circ} \mathrm{C}$ ve $600^{\circ} \mathrm{C}$ 'deki 28 günlük basınç dayanımları bir araştırmada incelenmiştir (Sall Bideci, 2016). Tüm sıcaklıklarda basınç dayanımının kolemanit katkısı ile yükseldiği bulunmuştur. Basınç dayanımın sıcaklığın $200^{\circ} \mathrm{C}$ 'ye kadar artışı ile iyileştiği, ancak $600^{\circ} \mathrm{C}$ 'ye kadar artışı ile kötüleştiği belirlenmiştir. Beton numunelerin $20-1000^{\circ} \mathrm{C}$ aralığındaki TG/DTA eğrilerine göre, kolemanit katk1lı numunelerde kütle kaybının daha fazla olduğu saptanmıştır. $\mathrm{Bu}$ durum, kolemanit mineralinin ortamdaki su miktarını arttırmasına atfedilmiştir. $\mathrm{Bu}$ çalışmadaki öğütülmemiş $\mathrm{C}-3 \mathrm{~mm}$ malzemesinin ve ögütülmüş C-75 $\mu \mathrm{m}, \mathrm{C}-45 \mu \mathrm{m}, \mathrm{C}$ $25 \mu \mathrm{m}$ tozlarının TG/DTA eğrilerden ortama salınan su miktarının ögütme işlemi neticesinde değiştiğinin tespit edilmesi, beton numunelerin için seçilecek olan kolemanit mineraline dikkat edilmesi gerekliliğini açıkça göstermiştir. Örneğin, kütle kaybı C-3 mm malzemesi ve C-75 $\mu \mathrm{m}, \mathrm{C}-45$ $\mu \mathrm{m}, \mathrm{C}-25 \mu \mathrm{m}$ tozları için sirasiyla $200^{\circ} \mathrm{C}$ 'de $\% 0.2$, $\% 0.5, \% 10, \% 2.5$ iken, $600^{\circ} \mathrm{C}$ 'de ise $\% 13, \% 21$, $\% 25, \% 13$ 'tür.

Mikron ve nano boyutlu kolemanit mineralleri WMA karışımlara ilave edilmiş ve karışımların düşük sıcaklık performansı bir çalışmada irdelenmiştir (Kutuk ve Kutuk-Sert, 2020). Düşük sıcaklık performansında Isıl çatlaklara karşı asfalt direncinin mikron partikül boyutlu kolemanit minerali katkılı karışımlarda daha iyi olduğu sonucuna varılmıştır. Bunun olası nedenlerin birisi de büyük partikül boyutuna sahip mineralin yüksek ayrışma sıcaklı̆̆ına sahip olmasına dayandırılmıştır. Yapılan yorum bu çalışmada tespit edilen partikül boyutu-ayrışma sıcaklığı ilişkisi ile şu şekilde doğrulanmaktadır: Kolemanit mineralin daha küçük boyuta indirgenmesiyle, ayrışma sıcaklığı DTG eğrisine göre $15^{\circ} \mathrm{C}$ ve aynı zamanda DTA eğrisine göre ise $18^{\circ} \mathrm{C}$ düşmüştür.

\section{Sonuçlar}

Bor mineralleri arasında en çok rağbet görenlerden birisi olan kolemanit, yeryüzünde bol miktarda bulunmaktadır. Bu yüzden kolemanit minerali pek çok endüstri tarafindan tercih edilmektedir. Bu çalışma sayesinde toz teknolojisi açısından farklı partikül boyutuna sahip kolemanit minerallerinin TG/DTA eğrileri incelenmiş ve aşağıda verilen bulgular elde edilmiştir.

$\checkmark$ C-3 mm malzeme ile C-75 $\mu \mathrm{m}$ tozuna ait TG/DTA eğrilerinin davranışı yaklaşık aynıdır, yani 1sıl özellikleri benzerdir.

$\checkmark$ C-3 mm malzemeye ait TG/DTA eğrileri, C-45 $\mu \mathrm{m}$ ve C-25 $\mu \mathrm{m}$ tozlarına ait TG/DTA eğrilerine göre oldukça farklıdır. Bu sonuç, nano boyut için yapılan ögütme ve eleme işlemleri ile 1sıl özelliğin değiştiğini göstermiştir.

$\checkmark \mathrm{C}-25 \mu \mathrm{m}$ tozuna ait TG/DTA eğrileri ile diğerleri kıyaslandığında, eğrinin davranışı üzerine fark C-25 $\mu \mathrm{m}$ tozu için daha fazladır. Nedeni, üretim yöntemi esnasındaki mekaniksel işlemler neticesinde C-25 $\mu \mathrm{m}$ tozunun nanopartikül boyuta indirgenmesine dayandirılabilir.

$\checkmark$ Ögütülmüş C-25 $\mu \mathrm{m}$ tozu ile ayrışma sıcaklığı düşmüştür ve kristalize su miktarı azalmıştır. Daha önce yayımlanan bir çalışmada tespit edilmiş olan düşük yüzde oranında yüksek basınç dayanımı elde edilmesinin bir sebebi, bu netice ile izah edilebilir.

\section{Teşekkür}

Bu çalışma, Recep Tayyip Erdoğan Üniversitesi Bilimsel Araştırma Projeleri birimi tarafindan 2014.109.03.01 numarali proje ile maddi olarak desteklenmiştir. Başlangıç malzemelerini temin eden Eti Maden İşletmeleri Genel Müdürlüğüne teşekkürlerimizi sunarız. Makalenin inceleme ve değerlendirme aşamasında yapmış oldukları katkılardan dolayı editör ve hakemlere teşekkür ederiz.

\section{Kaynaklar}

Akpinar, S., Evcin, A. and Ozdemir, Y. (2017). Effect of calcined colemanite additions on properties of hard porcelain body. Ceramics International, 43(11), 8364-8371. https://doi.org/10.1016/j.ceramint.2017.03.178

Alizadeh, M., Sharifianjazi, F., Haghshenasjazi, E., Aghakhani, M. and Rajabi, L. (2015). Production of nanosized boron oxide powder by high-energy ball milling. Synthesis and Reactivity in Inorganic, Metal-Organic, and Nano-Metal Chemistry, 45(1), 11-14. https://doi.org/10.1080/15533174.2013.797438

Barluenga, G., Giménez, M., Sepulcre, A. and Palomar, I. (2018). Effect of full scale pumping at early age and on hardened microstructure and properties of SCC with fly ash in hot-dry curing conditions. Construction and Building Materials, 
191 ,

1128-1138.

https://doi.org/10.1016/j.conbuildmat.2018.10.1 10

Canakci, A., Varol, T., Cuvalci, H., Erdemir, F., Ozkaya, S. and Yalcin, E. D. (2014). Synthesis of novel CuSn10-graphite nanocomposite powders by mechanical alloying. Micro and Nano Letters, 9(2), 109-112. https://doi.org/10.1049/mnl.2013.0715

Eti Maden İşlemleri Genel Müdürlüğü (2013). Faaliyet Raporu: Bor kullanım alanlart. Erişim adresi http://www.sp.gov.tr/upload/xSPRapor/files/Dn B8S+Eti_Maden_13_FR.pdf

Han, W., Ma, Z., Liu, S., Ge, C., Wang, L. and Zhang, X. (2017). Highly-dispersible boron nitride nanoparticles by spray drying and pyrolysis. Ceramics International, 43(13), 10192-10200. https://doi.org/10.1016/j.ceramint.2017.05.045

Kutuk-Sert, T. (2016). Stability analyses of submicronboron mineral prepared by mechanical milling process in concrete roads. Construction and Building Materials, 121, 255-264. https://doi.org/10.1016/j.conbuildmat.2016.05.1 56

Kutuk, S. (2016). Influence of milling parameters on particle size of ulexite material. Powder Technology, 301, 421-428. https://doi.org/10.1016/j.powtec.2016.06.020

Kutuk, S. (2017). Öğütülmüş nano boyutlu kolemanit mineralinin elementel ve kristal yapı özellikleri. Erzincan Üniversitesi Fen Bilimleri Enstitüsü Dergisi, 10(2), 303-313. https://dergipark.org.tr/tr/pub/erzifbed/issue/323 $83 / 334656$

Kutuk, S. and Kutuk-Sert, T. (2017). Effect of PCA on nanosized ulexite material prepared by mechanical milling. Arabian Journal for Science and Engineering, 42(11), 4801-4809. https://doi.org/10.1007/s13369-017-2643-7

Kutuk, S. and Kutuk-Sert, T. (2019). TEM analysis of submicron colemanite mineral prepared with mechanical milling process. 4th International Conference on Civil Environmental Geology and Mining Engineering (pp.714-720). Trabzon.

Kutuk, S. and Kutuk-Sert, T. (2020). An examination of nanoparticle colemanite mineral added warm mix asphalt. Construction and Building Materials, 243, 118252. https://doi.org/10.1016/j.conbuildmat.2020.1182 52

Liu, J., Chen, H., Guan, B., Liu, K., Wen, J. and Sun, Z. (2018). Influence of mineral nano-fibers on the physical properties of road cement concrete material. Construction and Building Materials,
190 ,

287-293

https://doi.org/10.1016/j.conbuildmat.2018.09.0 25

Lotti, P., Comboni, D., Gigli, L., Carlucci, L., Mossini, E., Macerata, E., Mariani, M. and Gatta, G. D. (2019). Thermal stability and high-temperature behavior of the natural borate colemanite: An aggregate in radiation-shielding concretes. Construction and Building Materials, 203, 679686.

https://doi.org/10.1016/j.conbuildmat.2019.01.1 23

Ma, Z., Liu, Y., Cai, Q., Jiang, H. and Yu, L. (2013). Excellent $\mathrm{Jc}$ in the low-temperature sintered $\mathrm{MgB} 2$ superconductors consisted of uncompleted $\mathrm{MgB} 2$ phase and residual $\mathrm{Mg}$. Materials Chemistry and Physics, 141(1), 378382.

https://doi.org/10.1016/j.matchemphys.2013.05. 027

Pancar, E. B. (2016). Beton yol kaplamalarının yüzey sıcaklıklarının düşürülmesi için çözümler. Gazi Üniversitesi Fen Bilimleri Dergisi Part C: Tasarım ve Teknoloji, 4(4), 285-291. https://dergipark.org.tr/tr/pub/gujsc/issue/45198/ 565995

Pancar, E. B. and Akpinar, M. V. (2016). Temperature reduction of concrete pavement using glass bead materials. International Journal of Concrete Structures and Materials, 10(1), 39-46. https://doi.org/10.1007/s40069-016-0130-2

Ríos, J. D., Cifuentes, H., Leiva, C., García, C. and Alba, M. D. (2018). Behavior of High-Strength Polypropylene Fiber-Reinforced SelfCompacting Concrete Exposed to High Temperatures. Journal of Materials in Civil Engineering, $\quad 30(11), \quad 04018271$. https://doi.org/10.1061/(ASCE)MT.19435533.0002491

Sallı Bideci, Ö. (2016). The effect of high temperature on lightweight concretes produced with colemanite coated pumice aggregates. Construction and Building Materials, 113, 631640. https://doi.org/10.1016/j.conbuildmat.2016.03.1 13

Shariatmadar, F. S. and Pakdehi, S. G. (2017). Synthesis and characterization of aviation turbine kerosene nanofuel containing boron nanoparticles. Applied Thermal Engineering, 112, 1195-1204. https://doi.org/10.1016/j.applthermaleng.2016.0 9.015

Uysal, T., Mutlu, H. S. and Erdemoğlu, M. (2016). Effects of mechanical activation of colemanite (Ca2B6O11.5H2O) on its thermal transformations. International Journal of 
Mineral Processing, 151, 51-58. https://doi.org/10.1016/j.minpro.2016.04.006

Waclawska, I. (1997a). Thermal behaviour of mechanically amorphized colemanite: I. Thermal decomposition of ground colemanite. Journal of Thermal Analysis, 48(1), 145-154. https://doi.org/10.1007/BF01978974
Waclawska, I. (1997b). Thermal behaviour of mechanically amorphized colemanite: II. Internal structure reconstitution processes of ground colemanite. Journal of Thermal Analysis, $48(1)$, 155-161. https://doi.org/10.1007/BF01978975

Yunlu, K. (2016). Bor Bileşikleri, Sentez Yöntemleri, Özellikleri, Uygulamalar (First ed.). Ankara: BOREN. 